\title{
Nanoporous carbons obtained by carbonization of copolymers impregnated by salts
}

\author{
M. Sobiesiak
}

Received: 31 October 2012 / Accepted: 12 December 2012 / Published online: 22 December 2012

(C) The Author(s) 2012. This article is published with open access at Springerlink.com

\begin{abstract}
This paper demonstrates the results of research on influence of types of polymer and kinds of salts used for impregnation of the polymer on porous structure formation in the final carbonaceous product. The studies were performed in two stages. In the first stage, the role of polymer structure were mainly studied. To achieve the aim, three different porous copolymers (polyimide and two types of polyester) were impregnated with the same salts $\left(\mathrm{NiSO}_{4}\right.$, and the mixture of $\mathrm{AgNO}_{3}$ and $\left.\mathrm{Gd}\left(\mathrm{NO}_{3}\right)_{3}\right)$. In the second part of the study, only one polymer (polyimide) was impregnated by three mixtures of salts (chlorides, nitrates and sulphates of $\mathrm{K}, \mathrm{Cu}(\mathrm{II})$ and $\mathrm{Fe}(\mathrm{III})$ ). This approach allowed to evaluate the impact of the mixture of salts on porosity of the carbons, which were to be prepared.

The obtained results revealed that when the impregnation was applied as a method for activation and moulding of porosity of carbonaceous materials prepared from polymers, several factors should be taken into account. First of all, initial decomposition temperatures of the polymers and the salts should be compared to find out if carbonization and activation processes proceed simultaneously or not. If the copolymer was carbonized and gases were released from decomposing salts, they reacted each other and synergic effect of polymer and salts properties were observed. Such conditions favored the development of microporous structure of the obtained carbon. On the contrary, if the processes were
\end{abstract}

The work presented at Eighth International Symposium Surface Heterogeneity Effects in Adsorption and Catalysis on Solids (ISSHAC 8).

M. Sobiesiak ( $\varangle)$

Faculty of Chemistry, Maria Curie-Sklodowska University, pl. Maria Curie-Sklodowskiej 3, 20-031 Lublin, Poland

e-mail: magdalena.sobiesiak@umcs.pl separated in time because of high temperature of melting point of the salts more mesopores were retained.

Keywords Nanoporous carbons - Impregnation of polymers · Salts impregnation - Carbon preparation . Porous structure formation $\cdot$ DFT

\section{Introduction}

Porous carbons can be obtained from different naturals or synthetic materials e.g.: nut shells, fruit stones, coals, polymers. Formation of porous structure of carbon proceeds during thermal treatment and activation process.

For chemical activation oxidative gases, acids, hydroxides and salts can be used (Puziy et al. 2007; MorenoCastilla et al. 2000; Foo and Hameed 2011; Figueiredo et al. 1999). Activation by an impregnation method is relatively inexpensive and easy to performed. The basic steps, usually carried out, include: wet impregnation, drying and calcinations. An activating compound used in the process modify surface of substrate, by formation of functional groups and residue of metal species (generally oxides). Sometimes functionalization of the precursor surface can be necessary to performed, in order to improve wetting ability of hydrophobic substrates, like carbons or some polymers.

Each of the activating agents influences on the thermally treated material in peculiar way, depending on experimental conditions (Evans et al. 1999; Kocirik et al. 2001; LilloRodenas et al. 2003; Sobiesiak et al. 2010).

In this work influence of both the polymer precursor and the salts mixtures used in impregnation process on the formation of porous structure in polymer derived carbon materials were explained. Different properties of the salts such as 
melting point, initial decomposition temperature and products of decomposition were considered. In the case of the copolymers used for carbonization, their thermal resistance and porous structure parameters were taken into account.

\section{Experimental}

In order to examine how the mixture of salts influences porous structure formation of the obtained carbons an impregnation method was applied. The studies were divided into two stages. In the first stage, three different porous copolymers and one mixture of salts were used. It was assumed that decomposition of the salts in mixture proceeds always in the same way regardless of polymeric surroundings. The assumption allowed to estimate mainly the impact of the polymers on the structure of the final carbonaceous products, but influence of salts mixture was also noticed.

Three bead-shaped copolymers 4,4'-bis(maleimido) diphenyl methane-divinylbenzene (BM-DVB), 2,3-epoxypropyl methacrylate-divinylbenzene (GLY-DVB) and 2,3-bis(2-hydroxy-3-methyl acryloyloxypropoxy)naphthalene-divinylbenzene (NAF-DVB) were synthesized by suspension copolymerization and next used as polymeric precursors for preparation of the carbons. Detailed description regarding preparation of copolymers and their full characteristics can be found in previously published works of Sobiesiak and Podkoscielna (2010) and Gawdzik and Sobiesiak (2003).

The obtained porous copolymers were dried and then impregnated with aqueous solutions of $\mathrm{NiSO}_{4}$, and mixture of $\mathrm{AgNO}_{3}$ and $\mathrm{Gd}\left(\mathrm{NO}_{3}\right)_{3}$. Concentration of each salt in the solution or mixture was $0.5 \mathrm{M} / \mathrm{L}$. Impregnation ratio was equal to half of mole of each salt per one kilogram of dried polymer. The impregnated polymers were left until they become thoroughly dry. Next, the obtained materials were carbonized at $800{ }^{\circ} \mathrm{C}$ in nitrogen atmosphere. The process lasted $1 \mathrm{~h}$. The carbons prepared from BM-DVB, GLY-DVB and NAF-DVB copolymers were labeled as C-BM-NiAgGd, C-GLY-NiAgGd and C-NAF-NiAgGd, respectively.

In the second stage of the studies, only BM-DVB copolymer was used. In this approach the influence of the polymer was the same in all cases, and the observed changes were the result of the differences in properties of the impregnating salts. In this case influence of the mixtures of salts (with the same metal cations) on synthesized carbons porous structure formation was evaluated.

The portion of the polymer was impregnated successively with the mixtures of sulphates, chlorides and nitrates of $\mathrm{K}$, $\mathrm{Cu}$ (II), $\mathrm{Fe}(\mathrm{III})$ dissolved in distilled water then dried and carbonized according to the same procedure as described above. The synthesized carbons were labeled as C-BM-SO $\mathrm{C}-\mathrm{BM}-\mathrm{Cl}$ or $\mathrm{C}-\mathrm{BM}-\mathrm{NO}_{3}$, where $\mathrm{C}-\mathrm{BM}$ meant carbonized copolymer BM-DVB and further part of the name indicated the one common anion in the mixture of salts.
Porous structure of the obtained carbon materials were characterized using the nitrogen sorption experiments performed at $77 \mathrm{~K}$ with adsorption analyzer AUTOSORB1CMS (Quantachrome Instruments, USA). Before analysis, the samples were outgassed at $140{ }^{\circ} \mathrm{C}$. The specific surface area was calculated using the standard multipoint BET method, while the total pore volume was calculated as the volume of liquid adsorbate at the relative pressure of about 0.99 . To evaluate nanoporous structure of the samples the NLDFT (the nonlocal density functional theory) method was used. For calculation purposes, equilibrium model of nitrogen sorption on carbon at $77 \mathrm{~K}$ was chosen. It was assumed that shape of pores was slit and/or cylindrical.

The analysis of chemical structure of the studied materials was based on SEM-EDX analysis carried out with Zeiss Ultra Plus FE-SEM equipped with Bruker AXS EDX detector $125 \mathrm{eV}$ resolution (mapped under $20 \mathrm{keV}$ ) and FTIR spectrometry in transmissions mode using $\mathrm{KBr}$ pellets with the sample contents about $3 \%$ (Tensor 27, Bruker). Before FTIR analysis the carbons were ground in a ceramic mortar to fine powder and dried in a vacuum dryer at $110^{\circ} \mathrm{C}$ for $24 \mathrm{~h}$.

\section{Results and discussion}

Despite during syntheses of the copolymers the same conditions were applied, the polymeric products possessed different porous structure. The pore size distribution (PSD) curves obtained for parent copolymers are shown in Fig. 1. From these data, one can see that GLY-DVB and BM-DVB possess a broad PSD, whereas for NAF-DVB it is relatively narrow.

\subsection{Influence of polymer structure on carbonaceous product formation in the impregnation method}

Using the same mixture of salts, the same way of impregnation, and identical carbonization conditions but different polymeric precursors, it was possible to evaluate the importance of polymer structure for porosity formation in the final products. Also influence of the salts (which was assumed to be the same in all cases) on their porous structure was possible to observed.

Figure 2 presents the changes in porous structure after carbonization of the polymers impregnated by the salts $\left(\mathrm{NiSO}_{4}, \mathrm{AgNO}_{3}\right.$, and $\left.\mathrm{Gd}\left(\mathrm{NO}_{3}\right)_{3}\right)$. In all cases, shrinkage of polymer pores characteristic for carbonization was observed. This effect was the strongest for GLY-DVB copolymer, that did not possess elements stabilizing its structure during carbonization. The PSD curve for this carbon shows two well separated regions. The first one, connected with the presence of micropores, is narrow (from 15 to $20 \AA$ ), while the second is wide and shows the presence of mesopores. 
Fig. 1 Pore size distributions of the precursor polymers:

BM-DVB, GLY-DVB and

NAF-DVB (Color figure online)

Fig. 2 Pore size distributions of the carbons obtained by carbonization of the parent polymers impregnated with the mixture of $\mathrm{NiSO}_{4}, \mathrm{AgNO}_{3}$ and $\mathrm{Gd}\left(\mathrm{NO}_{3}\right)_{3}$ (Color figure online)
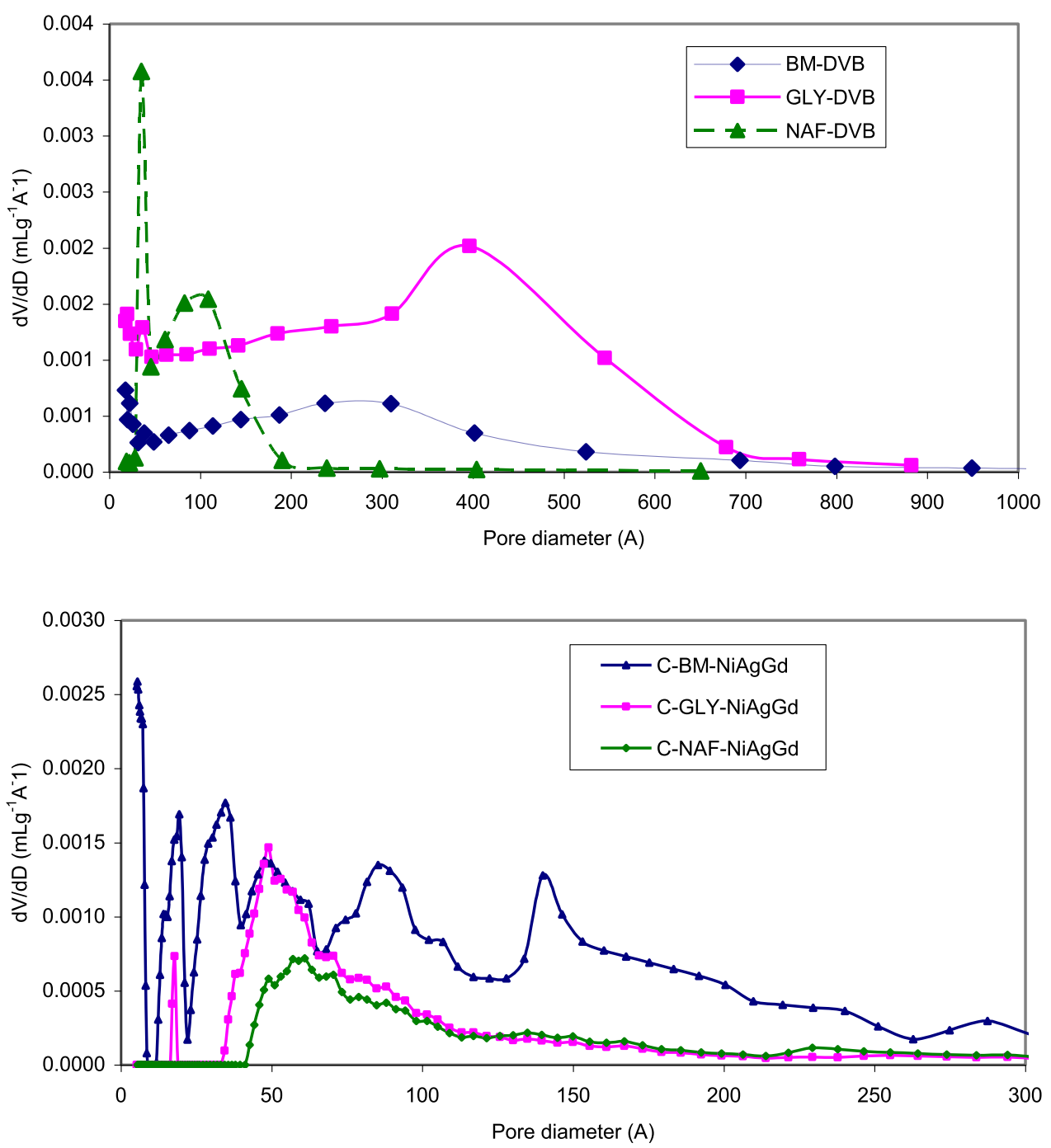

Shrinkage of NAF-DVB copolymer was smaller. This phenomenon could be explained by the fact that the naphthalene rings stabilized polymer structure and prevented its contraction. Probably this is one of the reasons, why the obtained carbon is thoroughly mesoporous.

BM-DVB was the polymer with very stable porous structure (aromatic rings and nitrogen atoms) consequently after carbonization many of pores were retained. Pore size distribution curve for the carbon C-BM-NiAgGd indicated multimodal system of pores. In case of this material, the influence of the salts mixture on porous structure formation is the most strongly noticed.

Quantitative data of percentage contributions of microand mesopores and other parameters characterizing porous structure of the precursor copolymers and all the carbonaceous materials presented in this work are collected in Table 1 .

According to the works of Maneva et al. (1990), Kwon et al. (2005), Melnikov et al. (2012) thermal decomposi- tion of the $\mathrm{NiSO}_{4}, \mathrm{AgNO}_{3}$, and $\mathrm{Gd}\left(\mathrm{NO}_{3}\right)_{3}$ takes place in the range of 230 to $800{ }^{\circ} \mathrm{C}$ and leads to releasing reactive gaseous products such as steam, $\mathrm{SO}_{3}, \mathrm{NO}_{2}, \mathrm{~N}_{2} \mathrm{O}_{5}$, and $\mathrm{O}_{2}$. These gases possess oxidative properties and they are able to interact with the polymeric precursors, which decompose in similar range of temperatures $\left(300-550{ }^{\circ} \mathrm{C}\right)$. The proceeding processes affect the formation of porous structure and functional groups on the surface.

Since the process of impregnation is carried out in aqueous solution, $\mathrm{Ag}_{2} \mathrm{SO}_{4}$ can precipitate in porous structure of the copolymers. This process causes blocking of porous structure by precipitating settlings and partially prevents of the pores collapse. However, activation with silver sulphate has no practical significance, as thermal decomposition of $\mathrm{Ag}_{2} \mathrm{SO}_{4}$ takes place at about $1050{ }^{\circ} \mathrm{C}$, that is much higher than maximum temperature of the carbonization in these studies. For that reason $\mathrm{SO}_{2}$ and $\mathrm{O}_{2}$ as gases released during decomposition of $\mathrm{Ag}_{2} \mathrm{SO}_{4}$ can be neglected. Detailed studies of this reaction was given by Savarino et al. (2001). 
Table 1 Structural parameters of studied carbon materials calculated from low temperature nitrogen adsorption isotherms

$S_{\mathrm{BET}}$ - specific surface area determined by the BET method.

$V_{\text {TOT }}$ - total pore volume at

$p / p_{0}=0.99 . V_{\mathrm{mi}}$-micropore volume determined by the DR method. $V_{\text {me }}$-mesopore volume calculated as a difference between total pore volume and micropore volume

Fig. 3 FTIR spectrograms of the carbons C-BM-NiAgGd, C-GLY-NiAgGd, C-NAF-NiAgGd

\begin{tabular}{lcllllc}
\hline Sample name & $\begin{array}{l}S_{\mathrm{BET}} \\
{\left[\mathrm{m}^{2} \mathrm{~g}^{-1}\right]}\end{array}$ & $\begin{array}{l}V_{\mathrm{TOT}} \\
{\left[\mathrm{cm}^{3} \mathrm{~g}^{-1}\right]}\end{array}$ & $\begin{array}{l}V_{\mathrm{mi}} \\
{\left[\mathrm{cm}^{3} \mathrm{~g}^{-1}\right]}\end{array}$ & $\% \mathrm{mi}$ & $\begin{array}{l}V_{\mathrm{me}} \\
{\left[\mathrm{cm}^{3} \mathrm{~g}^{-1}\right]}\end{array}$ & $\% \mathrm{me}$ \\
\hline GLY-DVB & 165 & 0.894 & 0 & 0 & 0.894 & 100 \\
NAF-DVB & 72 & 0.204 & 0 & 0 & 0.204 & 100 \\
C-BM & 49.2 & 0.154 & 0.005 & 3.25 & 0.149 & 96.75 \\
C-BM-NiAgGd & 102 & 0.267 & 0.019 & 7.12 & 0.248 & 92.88 \\
C-GLY-NiAgGd & 81.6 & 0.171 & 0.008 & 4.68 & 0.163 & 95.32 \\
C-NAF-NiAgGd & 26.06 & 0.066 & 0 & 0 & 0.066 & 100 \\
C-BM-Cl & 292 & 0.472 & 0.026 & 5.51 & 0.446 & 94.49 \\
C-BM-NO & 283.8 & 0.247 & 0.107 & 43.32 & 0.140 & 56.68 \\
C-BM-SO & 49.8 & 0.05 & 0 & 0 & 0.050 & 100 \\
\hline
\end{tabular}

FTIR spectra for the analyzed carbons, presented in Fig. 3, are similar to each other especially in the wavenumber range of 1700 to $900 \mathrm{~cm}^{-1}$. The bands in this range are the results of the salts presence. The very broad signals indicate variety of chemical species on the surface of the materials. In this region, vibration of single and double bonds carbon-oxygen and carbon-nitrogen are characteristic. Interesting is the fact that there are some characteristic bands $\left(1384,1252,1092\right.$ and $\left.800 \mathrm{~cm}^{-1}\right)$, which intensities increasing in the series C-BM-NiAgGd $\rightarrow$ C-GLY-NiAgGd $\rightarrow$ CNAF-NiAgGd. These bands are caused by stretching vibrations of bonds $\mathrm{O}=\mathrm{S}=\mathrm{O}\left(1140-1000 \mathrm{~cm}^{-1}\right), \mathrm{S}=\mathrm{O}(1225-$ $\left.980 \mathrm{~cm}^{-1}\right)$, S-O $\left(870-650 \mathrm{~cm}^{-1}\right), \mathrm{C}-\mathrm{S}\left(800-600 \mathrm{~cm}^{-1}\right)$ present in sulphonic and sulphinic compounds as well as anions thiosulphate (VI), $\mathrm{S}_{2} \mathrm{O}_{3}^{2-}$ (1660-1620 and 1000$\left.990 \mathrm{~cm}^{-1}\right)$ and sulphate $\left(1130-1080\right.$ and $680-580 \mathrm{~cm}^{-1}$ ) (Socrates 2001; Zieliński 2000, and On-Line Spectroscopic $\mathrm{Tool}^{1}$ ). The results of elemental analysis confirm this observation (Table 2). The contents of oxygen and sulphur increases in ratio 1:2:3. Total amounts of $\mathrm{Ni}, \mathrm{Ag}$, and $\mathrm{Gd}$ are

\footnotetext{
${ }^{1}$ On-Line Spectroscopic Tool. http://www.science-and-fun.de/tools/.
}

very high and make from 20 to $40 \%$ of mass of the carbon sample, proving that the metals in the form of oxides and salts were partially trapped in the porous structure during heat treatment. The highest contents of gadolinium are observed for carbons, which polymeric precursors possessed broad PSD (Fig. 1). This means the metal was trapped in the network during carbonization. In case of C-NAF-NiAgGd, the contents of nickel and silver are high, while the contents of gadolinium is the lowest. The copolymer NAF-DVB had the narrow pore size distribution, consequently small amount of wide pores was available for gadolinium nitrate to crystallize, so less gadolinium was built in the carbon structure. The above explains, why relatively low values of specific surface areas and total pore volume for materials of this series (and particularly for C-NAF-NiAgGd) were obtained.

\subsection{Influence and properties of salts mixture on carbonaceous product formation in the impregnation method}

In this step of the studies influence of different salts (with the same metal cations) on porous structure formation of the synthesized carbons was evaluated. PSD plots for the pre- 
Table 2 Percentage contents of elements in the studied materials

\begin{tabular}{|c|c|c|c|c|c|c|c|}
\hline $\begin{array}{l}\text { Elements } \\
\text { contents } \\
{[\%]}\end{array}$ & $\mathrm{C}-\mathrm{BM}$ & C-BM-NiAgGd & C-GLY-NiAgGd & C-NAF-NiAgGd & $\mathrm{C}-\mathrm{BM}-\mathrm{Cl}$ & $\mathrm{C}-\mathrm{BM}-\mathrm{NO}_{3}$ & C-BM-SO 4 \\
\hline $\mathrm{C}$ & 87.79 & 68.80 & 44.94 & 35.80 & 94.64 & 83.42 & 79.54 \\
\hline $\mathrm{O}$ & 7.15 & 4.81 & 10.67 & 15.47 & 2.15 & 6.88 & 7.46 \\
\hline $\mathrm{N}$ & 5.06 & 1.34 & 1.76 & 2.07 & 1.16 & 1.71 & 2.61 \\
\hline$S$ & & 2.92 & 3.71 & 7.77 & & & 2.65 \\
\hline $\mathrm{Cl}$ & & & & & 0.53 & & \\
\hline $\mathrm{Ni}$ & & 3.13 & 7.88 & 14.43 & & & \\
\hline $\mathrm{Ag}$ & & 2.03 & 4.21 & 14.16 & & & \\
\hline $\mathrm{Gd}$ & & 16.98 & 26.84 & 11.30 & & & \\
\hline $\mathrm{K}$ & & & & & 0.29 & 0.20 & 1.66 \\
\hline $\mathrm{Cu}$ & & & & & 0.34 & 3.17 & 3.66 \\
\hline $\mathrm{Fe}$ & & & & & 0.89 & 4.62 & 2.34 \\
\hline
\end{tabular}

Fig. 4 Pore size distributions of the carbons prepared by carbonization of the BM-DVB copolymer impregnated with the mixtures of sulphates, chlorides and nitrates of $\mathrm{K}, \mathrm{Cu}, \mathrm{Fe}$ (Color figure online)

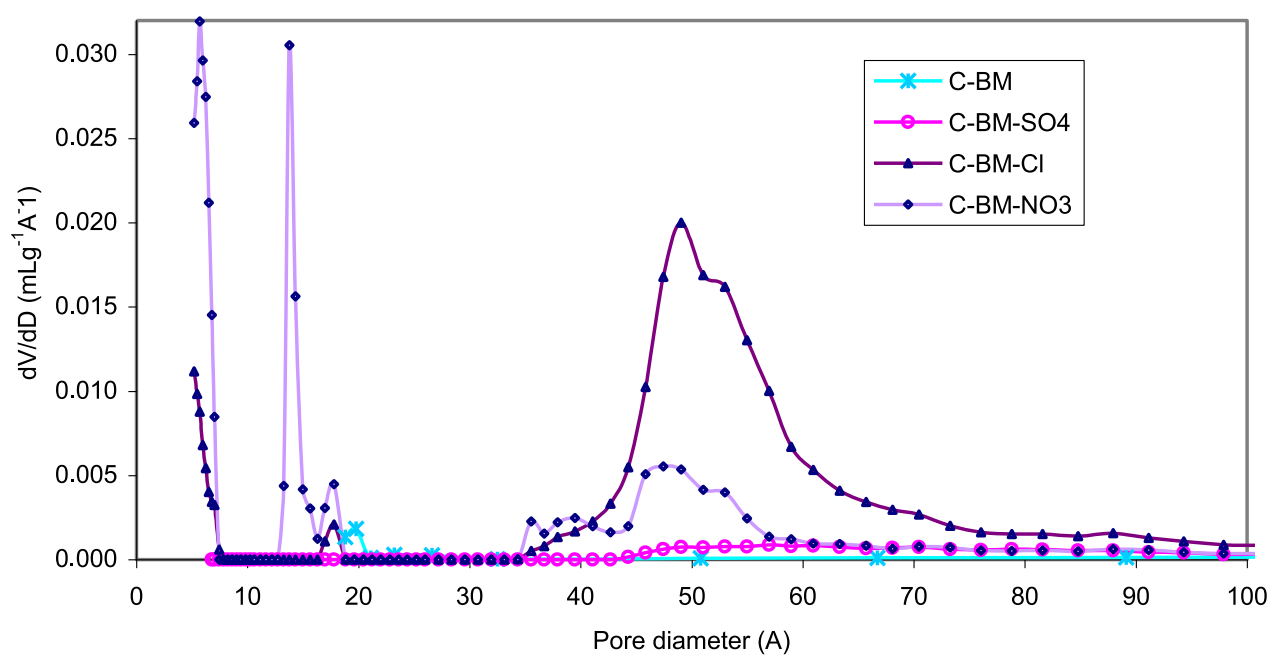

pared carbon materials are presented in Fig. 4. For comparison purposes, PSD curve for carbon, prepared without salts impregnation (C BM) was also included. This material had relatively small values of porous structure parameters (Table 1).

In this case impact of the salts presence on porosity of the final products is very clear. The largest influence on porous structure formation of the carbonaceous materials was observed when chlorides and nitrates were used for impregnation. In both cases specific surface areas reach value of about $300 \mathrm{~m}^{2} \mathrm{~g}^{-1}$ and PSD curves (Fig. 4) show the presence of ultramicropores $(<10 \AA)$, supermicropores $(10-20 \AA)$ and relatively narrow mesopores $(20-100 \AA)$. However, porous structures of these two materials are quite different.

$\mathrm{C}-\mathrm{BM}-\mathrm{Cl}$ possesses mainly mesopores with pore size distribution in the range of 35 to $95 \AA$. The contribution of micropores in the structure of this material is only $5.5 \%$ with the major part of ultramicropores.
Pore volume of C-BM-NO $\mathrm{NO}_{3}$ is almost two times smaller than that of $\mathrm{C}-\mathrm{BM}-\mathrm{Cl}$, and its structure is micro-mesoporous. Over $43 \%$ of pores form ultramicropores and supermicropores. In case of this carbon, PSD of mesopores is narrower and is in the range of 35 to $60 \AA$. The observed differences are the result of properties of the salts used for impregnation, particularly their thermal properties such as melting point, initial decomposition temperature, the way of decomposition and the type of released products.

The chlorides possess their melting temperatures in the range of $300-770{ }^{\circ} \mathrm{C}$, which means they still remain in the form of crystals (especially $\mathrm{KCl}$ ) when polymeric precursors decomposition process begins. This is the reason, why the collapse of polymeric structure is delayed in time and more mesopores are retained. The main gaseous products released from $\mathrm{CuCl}_{2} \cdot 2 \mathrm{H}_{2} \mathrm{O}$ and $\mathrm{FeCl}_{3} \cdot x \mathrm{H}_{2} \mathrm{O}$ while heating are $\mathrm{H}_{2} \mathrm{O}$ (from dehydration of crystals), $\mathrm{Cl}_{2}$ and $\mathrm{HCl}$ (Serban et al. 2004; Kanungo and Mishra 1996; potassium 
Fig. 5 FTIR spectrograms of the carbons C-BM, C-BM-Cl, $\mathrm{C}-\mathrm{BM}-\mathrm{NO}_{3}, \mathrm{C}-\mathrm{BM}-\mathrm{SO}_{4}$ (from the top)

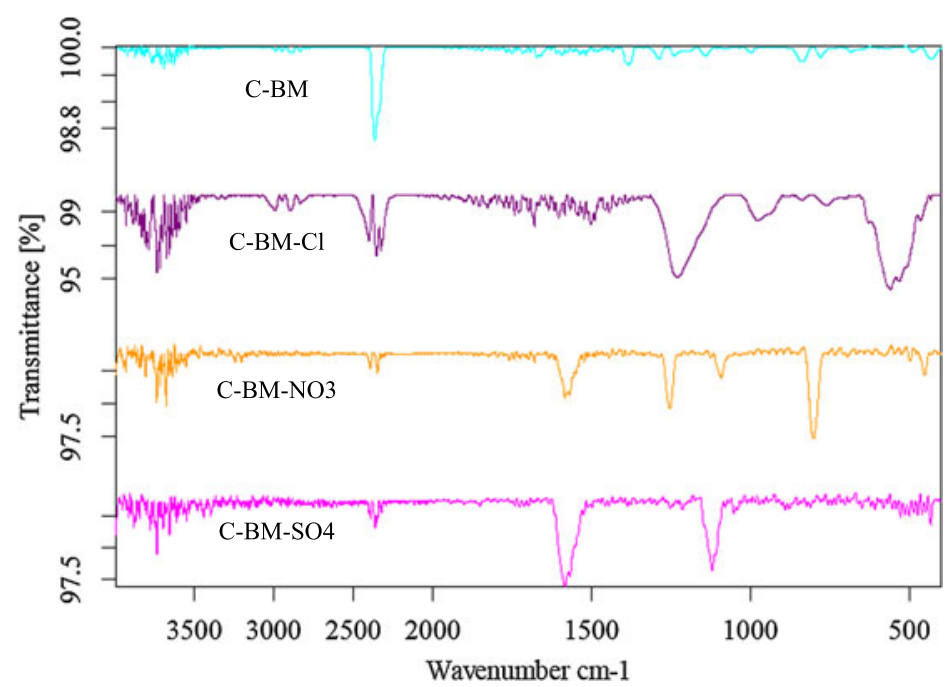

chloride $\mathrm{MSDS}^{2}$ ). Modification caused by these gases is observed in the FTIR spectra as chlorinated functional groups (Fig. 5). Two bands in the ranges of 1300-1060 and 650$480 \mathrm{~cm}^{-1}$ are broad and complex therefore they can be attributed to several types of vibrations. Waging of $\mathrm{C}-\mathrm{H}$ bonds in $\mathrm{CH}_{2}-\mathrm{Cl}$ groups $\left(1300-1150 \mathrm{~cm}^{-1}\right)$, stretching of $\mathrm{C}-\mathrm{Cl}$ bonds in aromatic compounds $\left(1100-1080 \mathrm{~cm}^{-1}\right)$, and deformations of $-\mathrm{COCl}$ groups in acyl chlorides (1300$900 \mathrm{~cm}^{-1}$ ) are responsible for existence of the former, while stretching of aliphatic $\mathrm{C}-\mathrm{Cl}$ bonds $\left(850-550 \mathrm{~cm}^{-1}\right)$ and inorganic species e.g. $\mathrm{ClO}_{3}^{-}\left(630-615,510-480 \mathrm{~cm}^{-1}\right)$ for the latter. The other signals can be attributed to cyclic anhydrides (stretching of C-O-C bonds-950-910 $\mathrm{cm}^{-1}$ ), vibrations of $-\mathrm{CCl}_{3}$ groups $\left(830-700 \mathrm{~cm}^{-1}\right)$ and vibrations $\mathrm{C}-\mathrm{H}$ bonds in $\mathrm{Cl}-\mathrm{C}-\mathrm{H}$ groups $\left(3080-2900 \mathrm{~cm}^{-1}\right)$ (Socrates 2001; Zieliński 2000; and On-Line Spectroscopic Tool).

Melting and decomposition processes of the nitrates proceed in lower temperatures $\left(150-400{ }^{\circ} \mathrm{C}\right)$. Released oxidative gases such as $\mathrm{H}_{2} \mathrm{O}, \mathrm{O}_{2}, \mathrm{HNO}_{3}, \mathrm{NO}_{2}$, and $\mathrm{NO}$ (Freeman 1957; potassium nitrite MSDS; ${ }^{3}$ Ding et al. 2002; L'vov and Novichikhin 1995; Morozov et al. 2003; WieczorekCiurowa and Kozak 1999) react immediately with polymeric precursor decomposing at the same time. This explains why, C-BM-NO $\mathrm{N}_{3}$ has the most microporous structure among the presented materials. On the surface of this carbon, nitrogen containing functional groups are present. The bands in the range of $1615-1530$ and $1290-1220 \mathrm{~cm}^{-1}$ are caused by asymmetric and symmetric stretching of $\mathrm{N}=\mathrm{O}$ bonds present in nitrates, nitrites nitro, and nitrosocompounds, respectively. The signal at $1090 \mathrm{~cm}^{-1}$ may be as-

${ }^{2} \mathrm{KCl}$ Material Safety Data Sheet. http://ull.chemistry.uakron.edu/ erd/Chemicals/8000/7705.html.

${ }^{3} \mathrm{KNO}_{3}$ Material Safety Data Sheet. http://ull.chemistry.uakron.edu/ erd/Chemicals/8000/6946.html. signed to $\mathrm{C}-\mathrm{N}$ bonds in aromatic species $\left(\sim 1100 \mathrm{~cm}^{-1}\right)$, but also to secondary alcohols $\left(1130-1000 \mathrm{~cm}^{-1}\right)$. Narrow and strong signal at about $800 \mathrm{~cm}^{-1}$ is the second nitrites characteristics vibration, besides above mentioned the one at $1250-1230 \mathrm{~cm}^{-1}$ (Socrates 2001; Zieliński 2000; and online spectroscopic tool).

The carbon prepared by impregnation with sulphates has similar specific surface area to the non-impregnated carbon-C BM, and its total pore volume is even three times lower. No micropores are accessible for $\mathrm{N}_{2}$ and widths of mesopores are in the range of 42 to $100 \AA$ A. FTIR spectra of this material show only two but intensive signals coming from sulphur containing compounds. Both of them are complex indicating that many different functionalities could reveal their presence. In the range of 1630 to $1500 \mathrm{~cm}^{-1}$ signals given by anions $\mathrm{S}_{2} \mathrm{O}_{3}^{2-}\left(1660-1620 \mathrm{~cm}^{-1}\right)$, vibrations of $\mathrm{C}=\mathrm{N}$ bonds $\left(1685-1580 \mathrm{~cm}^{-1}\right)$ and $\mathrm{C}=\mathrm{S}$ ones in thioamides and thiolactons $\left(1570-1460 \mathrm{~cm}^{-1}\right)$ can be observed. The band in the range of 1170 to $1080 \mathrm{~cm}^{-1}$ come from superposition of signals of following species: sulphinic acids $\left(1100-1090 \mathrm{~cm}^{-1}\right)$, sulphinic acid esters (1140$\left.1125 \mathrm{~cm}^{-1}\right)$, sulphones $\left(1170-1110 \mathrm{~cm}^{-1}\right)$, thioesters $(1210$ $\left.1080 \mathrm{~cm}^{-1}\right)$, thioamides and thiolactons $\left(1140-1090 \mathrm{~cm}^{-1}\right)$, and sulphates (1130-1080 $\mathrm{cm}^{-1}$ ) (Socrates 2001; Zieliński 2000; and On-Line Spectroscopic Tool).

According to papers by Petkova and Pelovski (2008), Mianowski and Bigda (2004), and Masset et al. (2006) copper and iron sulphates decompositions carry out gradually in the range of 250 to $700{ }^{\circ} \mathrm{C}$ and finally lead to copper (II) oxide and iron (III) oxide. The gases such as steam, $\mathrm{SO}_{3}, \mathrm{SO}_{2}$, and $\mathrm{O}_{2}$ are also evolved slowly and gradually. For this reason their oxidative properties are not so strongly marked, as in case of nitrates or chlorides. Potassium sulphate is thermally stable compound and decomposes at $1067{ }^{\circ} \mathrm{C}$ (accord- 
ing to its International Sheet of Chemical Safety ${ }^{4}$ ). This salt is unchanged in carbonization condition. High amount of potassium in C-BM-SO $\mathrm{S}_{4}$ proves, that the salt was trapped in porous structure of the material and could not be removed by washing. This conclusion explain the lowest value of total pore volume and absence of micropores in this material.

\section{Conclusions}

The results presented in this work demonstrate that both type of polymer and kind of salts used for impregnation had influence on process of porous structure formation. Among examined mixtures of salts-chlorides and nitrates were the most effective in the creation of porous structure of synthesized carbon materials. However, chlorides produced mesoporous material, while nitrates micro-mesoporous one. The mixture of sulphates produced mesoporous carbon, but its porous structure was not strongly developed.

While applying impregnation as a method for activation and moulding porosity of carbonaceous materials prepared from polymers, several factors should be taken into account.

The kind of used salts mixture had the crucial influence for development of carbon porous structure. Melting point and initial decomposition temperature were properties having fundamental meaning for the process. Also properties of the evolved gaseous products (oxidative gases, acids) had important impact. Proper selection of these factors allows to design type of porosity in the final product. General rules are as follow:

- the higher value of melting point is, the more mesopores will be retained

- the lower decomposition temperature of salts is, the more micropores will be obtained

- the reactive gases evolved during decomposition of salts modify chemical structure of carbonaceous product

- the higher is rate of salts decomposition, the stronger is the influence of released gases chemical nature,

- some amount of metals (especially in form of sparingly soluble salts or oxides) is built in the structure of prepared carbon.

In case of polymeric precursors, the most important are thermal resistance of polymeric networks and chemical structure that can stabilize their porous structure. The carbonized copolymer and the released gases react with each other, therefore synergic effect of both polymer and salts properties can be observed.

\footnotetext{
${ }^{4}$ Potassium Sulphate (ICSC: 1451): International Sheet of Chemical Safety, International Programme on Chemical Safety. http://www. ilo.org/dyn/icsc/showcard.display?p_lang=en\&p_card_id=1451
}

Open Access This article is distributed under the terms of the Creative Commons Attribution License which permits any use, distribution, and reproduction in any medium, provided the original author(s) and the source are credited.

\section{References}

Ding, Z., Martens, W., Frost, R.L.: Thermal activation of copper nitrate. J. Mater. Sci. Lett. 21, 1415-1417 (2002)

Evans, M.J.B., Halliop, E., MacDonald, J.A.F.: The production of chemically-activated carbon. Carbon 37, 269-274 (1999)

Figueiredo, J.L., Pereira, M.F.R., Freitas, M.M.A., Orfao, J.J.M.: Modification of the surface chemistry of activated carbons. Carbon 37, 1379-1389 (1999)

Foo, K.Y., Hameed, B.H.: Utilization of rice husks as a feedstock for preparation of activated carbons by microwave induced $\mathrm{KOH}$ and $\mathrm{K}_{2} \mathrm{CO}_{3}$ activation. Bioresour. Technol. 102, 9814-9817 (2011)

Freeman, E.S.: The kinetics of the thermal decomposition of potassium nitrate and of the reaction between potassium nitrite and oxygen. J. Am. Chem. Soc. 79, 838-842 (1957). doi:10.1021/ja01561a015

Gawdzik, B., Sobiesiak, M.: Chemical composition of plasma treated polyimide microspheres. Appl. Surf. Sci. 214, 52-57 (2003)

Kanungo, S.B., Mishra, S.K.: Thermal dehydration and decomposition of $\mathrm{FeCl}_{3} \cdot x \mathrm{H}_{2} \mathrm{O}$. J. Therm. Anal. 46, 1487-1500 (1996)

Kocirık, M., Brych, J., Hradil, J.: Carbonization of bead-shaped polymers for application in adsorption and in composite membranes. Carbon 39, 1919-1928 (2001)

Kwon, J.-W., Yoon, S.H., Lee, S.S., Seo, K.W., Shim, I.-W.: Preparation of silver nanoparticles in cellulose acetate polymer and the reaction chemistry of silver complexes in the polymer. Bull. Korean Chem. Soc. 26, 837-840 (2005)

Lillo-Rodenas, M.A., Cazorla-Amoros, D., Linares-Solano, A.: Understanding chemical reactions between carbons and $\mathrm{NaOH}$ and $\mathrm{KOH}$. An insight into chemical activation mechanism. Carbon 41, 267-275 (2003)

L'vov, B.V., Novichikhin, A.V.: Mechanism of thermal decomposition of hydrated copper nitrate in vacuo. Spectrochim. Acta, Part B, At. Spectrosc. 50, 1459-1468 (1995)

Maneva, M., Rizova, D., Genov, L., Liptay, G.: On the thermal decomposition of $\mathrm{NiSO}_{4} \cdot n \mathrm{H}_{2} \mathrm{O}(n=7,6,4,1)$ and of their deuterated analogs. J. Therm. Anal. 36, 915-922 (1990)

Masset, P., Poinso, J.-Y., Poignet, J.-C.: TG/DTA/MS study of the thermal decomposition of $\mathrm{FeSO}_{4} \cdot 6 \mathrm{H}_{2} \mathrm{O}$. J. Therm. Anal. Calorim. 83, 457-462 (2006)

Melnikov, P.P., Nascimento, V.A., Zanoni Konsolo, L.Z.: Computerized modeling of intermediate compounds formed during thermal decomposition of gadolinium nitrate hydrate. Russ. J. Phys. Chem. 86, 1659-1663 (2012)

Mianowski, A., Bigda, R.: The Kissinger law and isokinetic effect. Part II. Experimental analysis. J. Therm. Anal. Calorim. 75, 355-372 (2004)

Moreno-Castilla, C., Lopez-Ramon, M.V., Carrasco-Marın, F.: Canges in surface chemistry of activated carbons by wet oxidation. Carbon 38, 1995-2001 (2000)

Morozov, I.V., Znamenkov, K.O., Korenev, Yu.M., Shlyakhtin, O.A.: Thermal decomposition of $\mathrm{Cu}\left(\mathrm{NO}_{3}\right)_{2} \cdot 3 \mathrm{H}_{2} \mathrm{O}$ at reduced pressures. Thermochim. Acta 403, 173-179 (2003)

Petkova, V., Pelovski, Y.: Comparative DSC study on thermal decomposition of iron sulphates. J. Therm. Anal. Calorim. 93, 847-852 (2008) 
Puziy, A.M., Poddubnaya, O.I., Gawdzik, B., Sobiesiak, M., Tsyba, M.M.: Phosphoric acid activation-functionalization and porosity modification. Appl. Surf. Sci. 253, 5736-5740 (2007)

Savarino, J., Alexander, B., Darmohusodo, V., Thiemens, M.H.: Sulfur and oxygen isotope analysis of sulfate at micromole levels using a pyrolysis technique in a continuous flow system. Anal. Chem. 73, 4457-4462 (2001)

Serban, M., Lewis, M.A., Basco, J.K.: Kinetic Study of the Hydrogen and Oxygen Production Reactions in the Copper-Chloride Thermochemical Cycle (2004). http://hydrogen.uoit.ca/assets/ Default/documents/Public/Lewis-AIChE04.pdf

Socrates, G.: Infrared and Raman Characteristic Group Frequencies. Tables and Charts, pp. 283-327. Wiley, New York (2001). Chap. 22
Sobiesiak, M., Gawdzik, B., Puziy, A.M., Poddubnaya, O.I.: Analysis of structure and properties of active carbons and their copolymeric precursors. Appl. Surf. Sci. 256, 5355-5360 (2010)

Sobiesiak, M., Podkoscielna, B.: Preparation and characterization of porous DVB copolymers and their applicability for adsorption (solid-phase extraction) of phenol compounds. Appl. Surf. Sci. 257, 1222-1227 (2010)

Wieczorek-Ciurowa, K., Kozak, A.J.: The thermal decomposition of $\mathrm{Fe}\left(\mathrm{NO}_{3}\right)_{3} \times 9 \mathrm{H}_{2} \mathrm{O}$. J. Therm. Anal. Calorim. 58, 647-651 (1999)

Zieliński, W.: Metody Spektroskopowe i Ich Zastosowanie do Identyfikacji Związków Organicznych, pp. 614-642. Wydawnictwo Naukowo-Techniczne, Warszawa (2000) 